\title{
The value of pre-operative ultrasound mapping of the greater saphenous vein prior to 'closed' in situ bypass operations
}

\author{
Lukas C. van Dijk*a , Cees H.A. Wittens ${ }^{\mathrm{b}}$, Herman Pieterman ${ }^{\mathrm{a}}$, Hero van Urk \\ 'Department of Radiology, University Hospital Rotterdam 'Dijkzigt', Dr Molewaterplein 40, 3015 GD Rotterdam, The Netherlands \\ bepartment of Surgery, St. Franciscus Hospital, Rotterdam. The Netherlands \\ 'Department of Vascular Surgery, University Hospital Rotterdam 'Dijkzigt', Rotterdam, The Netherlands
}

Received 24 January 1996; revised 30 January 1996; accepted 17 March 1996

\begin{abstract}
Objective: The aim of this study was to test pre-operative ultrasound mapping for the detection of duplications and narrow vein segments of the greater saphenous vein (GSV) used as bypass for occlusive arterial disease surgery. Patients and methods: In 44 patients pre-operative ultrasound findings of duplications and lumen assessment of the GSV were compared to the per-operative findings. Results: In nine patients (20\%) the pre-operative ultrasound examination showed a duplication. Pre-operative ultrasound had missed a duplication in two cases but had instead shown a narrow segment in both. The pre-operative ultrasound assessment of lumen diameter showed a narrow lumen segment in 10 of the 44 patients. In one patient a per-operatively narrow lumen had not been seen on pre-operative ultrasound. Conclusion: Pre-operative ultrasound mapping of the GSV is a sensitive tool for detection of duplications and narrow vein segments. Since these anatomical variations provide important information for the vascular surgeon, before performing a 'closed' in situ bypass operation, pre-operative vein mapping should be considered when planning such a procedure.
\end{abstract}

Keywords: Ultrasound studies, saphenous vein; Veins, greater saphenous; Veins, US study; Veins, surgery

\section{Introduction}

It is generally accepted that autologous vein is the prefered bypass material for surgical arterial reconstruction in the lower extremity since it offers the best patency rates. Usually the greater saphenous vein (GSV) is chosen if it is of sufficient quality to serve as an arterial bypass. The GSV can either be used 'reversed' or 'in situ'. When the reversed technique is chosen, the GSV is removed over the length necessary for the bypass. Subsequently the vein is anastomosed reversed, i.e. the distal end is anastomosed proximally and vice versa. Reversal is necessary because the valves in the vein would otherwise hamper the arterial blood flow. All side branches of the vein are ligated during the removal of the vein. As the name 'in situ' suggests, this technique,

\footnotetext{
* Corresponding author, Tel.: +31 10 4633213; Fax: +31 10 4634033.
}

in contrast to the reversed technique, leaves the GSV in its anatomical place. To achieve an adequate bypass, this technique requires that the valves in the vein are rendered insufficient and the side branches of the vein ligated. Usually this technique is performed 'open', i.e. the GSV is exposed over the entire length needed for the bypass. This 'open' technique leads to a high number of post-operative wound complications: Reifsnyder et al. reported $34 \%$ wound complications in a retrospective study [1].

Recently modifications of the 'in situ' bypass technique have been proposed to reduce the length of the skin incision and thereby the number of wound complications $[2,3]$. Two procedures are necessary for these 'closed' in situ bypass techniques: (1) the blind cutting of the valves of the greater saphenous vein (GSV), and (2) per-operative coil embolisation of the side branches of the GSV. In a previous article, we noted that two anatomical aspects of the GSV in particular are impor- 
Table 1

Patient characteristics and indications for surgery

\begin{tabular}{ll}
\hline Patient characteristics & \\
\hline Male:female & $29: 15$ \\
Age (years) & 70 \\
Operation indication & \\
Fontaine II:III:IV $^{2}$ & $15: 10: 19$ \\
Diabetes & $18 \%$ \\
Smoking & $30 \%$ \\
Hypertension & $25 \%$ \\
Ischaemic heart disease & $41 \%$ \\
\hline
\end{tabular}

Fontaine classification: II, intermittant claudication (in all patients IIb, walking distance $<100 \mathrm{~m}$ ); III, rest pain; IV, ulcus and/or necrosis.

tant determinants for a successful 'closed' in situ bypass procedure, namely, the occurrence of duplications and narrow segments of the GSV [3].

B-mode ultrasound scanning as described by Leopold et al. [4] is considered the best way to perform preoperative examination of the GSV. The aim of this study was to test the efficacy of pre-operative ultrasound mapping of the GSV for detection of duplications and narrow vein segments.

\section{Patients and methods}

In 44 patients with arterial obstructive disease, in which a venous bypass with a below knee distal anastomosis was planned, pre-operative ultrasound examination of the GSV was performed less than 1 week prior to surgery. Characteristics and indications for the arterial reconstruction are shown in Table 1. An in situ bypass ('open' or 'closed') was performed. In three patients however a 'semi-closed' procedure was performed, i.e. the side-branches were ligated via separate small skin incisions, because the operator was not yet familiarised with the 'closed' technique. The reversed

Table 2

Types of operative procedures performed

\begin{tabular}{lc}
\hline Types of surgical procedures $(N=44)$ & \\
\hline In situ femoro-popliteal $(N=22)^{\mathrm{a}}$ & 12 \\
"Open" & 9 \\
"Closed" & 1 \\
"Semi-closed" & 9 \\
In situ femoro-crural $(N=13)$ & 2 \\
"Open" & 2 \\
"Closed" & 1 \\
"Semi-closed" & 2 \\
Reversed femoro-popliteal" & 6 \\
Reversed femoro-crural & \\
Prosthetic bypass & \\
\hline
\end{tabular}

${ }^{2}$ Femoro-popliteal bypasses always with a distal anastomosis below knee joint level.
Table 3

Duplications $(N=44)$ of the greater saphenous vein. Pre-operative ultrasound vein mapping findings compared to per-operative findings

\begin{tabular}{lll}
\hline Pre-operative & \multicolumn{2}{l}{ During operation } \\
\cline { 2 - 3 } & Normal & Duplication \\
\hline Normal & 33 & 2 \\
Duplication & 3 & 6 \\
\hline
\end{tabular}

GSV technique was used if the ipsilateral GSV was not available or considered inadequate per-operatively and the contralateral GSV was acceptable. A prosthetic bypass was used if no adequate GSV was available at all. Veins of other parts of the body were not used. Also no composed grafts were used in this study. Table 2 shows the numbers of the different operative procedures.

The pre-operative ultrasound vein mapping was performed with a Dornier AI 3200 B-mode ultrasound scanner. A 7.5-mHz linear array transducer was used. Patients were examined with the leg in a vertical position: standing or sitting on a high chair with the examined leg dangling. If the ipsilateral vein was considered not suitable for a bypass, the contralateral GSV was also examined. The pre-operative ultrasound and peroperative visual aspects of the GSV were described as follows: (1) the occurrence of duplications was scored; (2) the diameter of the vein was assessed for stenoses.

The pre-operative ultrasound criterion for a narrow segment was if the smallest venous lumen diameter $<2.0$ $\mathrm{mm}$. The per-operative criterion was a subjective judgement of narrowness by the surgeon, without the use of a caliper or other measurement since only outer diameter and not lumen diameter was assessed peroperatively.

The ultrasound findings were pre-operatively available to the surgeon. There was an agreement that the findings on ultrasound were not to be considered a reason for not using the vein as a bypass without peroperative inspection of the vein.

\section{Results}

In nine patients $(20 \%)$ the pre-operative ultrasound examination showed a duplication of the GSV (Table 3).

Table 4

Diameter assessment $(N=44)$ of the greater saphenous vein. Preoperative ultrasound vein mapping findings compared to subjective per-operative findings

\begin{tabular}{lll}
\hline Pre-operative & \multicolumn{2}{l}{ During operation } \\
\cline { 2 - 3 } & Normal & Narrow \\
\hline Normal & 33 & 1 \\
Narrow (<2 mm) & 4 & 6 \\
\hline
\end{tabular}


Pre-operative ultrasound had missed a duplication in two cases but had instead shown a narrow segment with a lumen $<2 \mathrm{~mm}$ in both.

The pre-operative ultrasound assessment of lumen diameter showed a narrow lumen segment in 10 of the 44 patients (Table 4).

\section{Discussion}

Pre-operative ultrasound mapping of the GSV allows visualisation of duplications and narrow segments of the GSV. With pre-operative vein mapping duplications of the GSV were observed in $20 \%$. Two duplications were missed with pre-operative ultrasound. In both patients pre-operative ultrasound had only shown a narrow vein segment, possibly one half of the duplicated segment. In three patients in which pre-operative ultrasound showed a duplication, this was not visualised per-operatively, possibly due to the fact that the duplicated part of the GSV was not explored totally and therefore the duplication could have been interpreted as being a side branch. If the pre-operatively and per-operatively demonstrated duplications are added, a total of 11 duplications in $\mathbf{4 4}$ legs $(25 \%)$ were seen. This figure lies between the $42 \%$ seen by Leopold et al. [5] and the $18 \%$ found by Ruoff et al. [6]. Both however only recorded the number of duplications seen with pre-operative ultrasound vein mapping and did not mention any 'missed' duplications encountered per-operatively.

When planning per-operative coil embolisation for a 'closed' in situ bypass technique, requiring endovascular catheter manipulation, an accurate pre-operative diameter assessment is essential since a lumen diameter of $\geq 3 \mathrm{~mm}$ is preferred [7,8]. The coil embolisation catheter we use has a 7-F $(2.1 \mathrm{~mm})$ diameter, therefore we consider a venous lumen diameter $<2 \mathrm{~mm}$ to be an absolute contra-indication for a closed in situ bypass. The pre-operative assessment showed a venous lumen with the smallest diameter $<2 \mathrm{~mm}$ in 10 patients. Only in one patient a per-operatively found narrow venous lumen was not anticipated pre-operatively with ultrasound. In four patients a narrow vein anticipated preoperatively was not considered to be narrow during the operation. The diameter of the GSV was examined with the patients leg in a vertical position. This may explain the apparent overestimation of the occurrence of narrow segments, since Blebea et al. showed that the optimal position for venous mapping, leading to the largest measured vein diameters, is not the vertical position but supine in combination with the use of a high-thigh tourniquet [9].

Pre-operative ultrasound vein mapping is a relatively inexpensive and unharmful investigation which can provide useful information when planning lower extremity vein bypass surgery. We have shown that the preoperative ultrasound mapping is a sensitive tool for the detection of duplications and narrow segments of the GSV. Therefore this safe and inexpensive investigation should be considered before planning a 'closed' in situ bypass procedure. Pre-operative vein mapping can be performed with the leg in a vertical position as we did, but the supine position with use of a high-thigh tourniquet is to be preferred [9].

\section{References}

[1] Reifsnyder T, Bandyk D, Seabrook G, Kinney E, Towne JB. Wound complications of the in situ saphenous vein bypass technique. J Vasc Surg 1992; 15: 843-850.

[2] Rosenthal D, Herring MB, O'Donovan TG, Cikrit DF, Comerota AH, Corson JD. Endovascular infrainguinal in situ saphenous vein bypass: a multicenter preliminary report. J Vasc Surg 1992; 16: 453-458.

[3] Wittens CHA, van Dijk LC, du Bois NAJJ, van Urk H. A new "closed" in situ bypass technique. Eur J Vasc Surg 1994; 8: 166-170.

[4] Leopold PW, Shandall AA, Corson JD, Shah DM, Leather RP, Karmody AM. Initial experience comparing B-mode imaging and venography of the saphenous vein before in situ bypass. Am J Surg 1986; 152: 206-210.

[5] Leopold PW, Shandall A, Kupinsky AM, Chang BB, Kaufman J, Shah DM, Leather RP. Role of B-mode venous mapping in infrainguinal in situ vein-arterial bypasses. Br J Surg 1989; 76: 305-307.

[6] Ruoff BA, Cranley JJ, Hannan LA, Aseffa N, Karkow WS, Stedje KG, Cranley RD. Real-time duplex ultrasound mapping of the greater saphenous vein before in situ infrainguinal revascularization. J Vasc Surg 1987; 8: 107-113.

[7] Cikrit DF, Dalsing MC, Lalka SG, Fiore NF, Sawchuk AP, Ladd AP, Solooki B. Early results of endovascular-assited in situ saphenous vein bypass grafting. J Vasc Surg 1994; 19: 778-787.

[8] van Dijk LC, van Urk H, du Bois NAJJ, Yo TI, Koning J, Jansen WBJ, Wittens CHA. A new "closed" in situ vein bypass technique results in a reduced wound complication rate. Eur $\mathbf{J}$ Vasc Endovasc Surg 1995; 10: 162-167.

[9] Blebea J, Schomaker WR, Hod G, Fowl RJ, Kempezinsky RF. Preoperative duplex venous mapping: a comparison of positional techniques in patients with and without atherosclerosis. $J$ Vasc Surg 1994; 20: 226-234. 